\title{
"Proyecto e-Book, una TAC para el aprendizaje centrado en el alumno"
}

DOI: $10.46932 / \mathrm{sfjdv} 2 \mathrm{n} 2-116$

Received in: March 1st, 2021

Accepted in: May 30th, 2021

\section{García-Cruz Karla Verónica \\ $\mathrm{PhD}$ en Ciencias}

Escuela Nacional Preparatoria No.8 "Miguel E. Schulz”, Universidad Nacional Autónoma de México Av. Lomas De Plateros S/N, Merced Gómez, Álvaro Obregón, 01600 Ciudad de México, CDMX E-mail: veronica.garcia@enp.unam.mx

\section{Cruz-Sánchez David}

Master en Ciencias Biológicas

Escuela Nacional Preparatoria No.8 "Miguel E. Schulz”, Universidad Nacional Autónoma de México Av. Lomas De Plateros S/N, Merced Gómez, Álvaro Obregón, 01600 Ciudad de México, CDMX E-mail: david.cruz@unam.mx

\section{RESUMEN}

En la actualización del programa de Biología IV del Bachillerato (ENP) de la UNAM señala que los profesores somos facilitadores de la enseñanza de los alumnos, esto significa que el alumno es el centro del proceso de enseñanza-aprendizaje mientras que el profesor proporciona el andamiaje necesario para guiarlo. Del mismo modo, dicho programa hace referencia al empleo de las TIC y las TAC durante el desarrollo de contenidos conceptuales y procedimentales. Por ello, empleamos los e-Books como herramienta digital para la construcción de conocimiento basado en el alumno, para dos temas de la Unidad 1 de dicho programa. El proceso fue el siguiente: primero, los alumnos realizaron búsquedas de información sobre las principales características y servicios ambientales de ecosistemas mexicanos. Después, para estructurar el trabajo, elaboraron un documento en Google Docs donde analizaron y sintetizaron su investigación. Finalmente, los alumnos elaboraron e-books con el fin de plasmar sus ideas y reflexionar sus conclusiones. Dicho material fue presentado en plenaria para desarrollar la difusión de ideas en público. En conclusión, los e-Books son herramientas digitales útiles para la construcción del aprendizaje centrado en el alumno, fomentan el trabajo colaborativo y forman parte de la alfabetización tecnológica, la cual es de suma importancia en la formación de nuestros educandos.

PALABRAS CLAVE: e-Books, Herramientas digitales, TIC-TAC, aprendizaje centrado en el alumno.

\section{INTRODUCCIÓN}

El rápido desarrollo en la tecnología digital e Internet han proporcionado muchos beneficios para la transferencia de información y comunicación. Estos cambios y desarrollos están directamente relacionados con la alfabetización digital porque han creado nuevos entornos y oportunidades para que las personas usen sus habilidades en el uso de herramientas de aprendizaje. El uso de las Tecnologías de la Información y la Comunicación (TIC) han sido un portal para estos nuevos entornos del aprendizaje (Ortiz Marín, et al. 2021), ya que son atractivas e intuitivas para los alumnos. Algunas de ellas derivaron como Tecnologías del Aprendizaje y el Conocimiento (TAC), ya que algunas de estas pueden ser 
utilizadas en cualquier nivel educativo con la finalidad de lograr el aprendizaje significativo en nuestros estudiantes (Destebasi. 2015; Santana Sardi, et al,. 2021).

Un e-Book está expresamente diseñado para poder ser leído por cualquier dispositivo electrónico que soporte sus características. Puede tener o no su versión impresa. Los e-Books tienen una distribución a nivel mundial, por su origen electrónico. También tienen la capacidad de incluir diferentes archivos multimedia, por ejemplo, imágenes, audio, video, ligas o vínculos. Dada esta virtud se pueden crear audio libros, combinar textos con videos y/o complementar con otras actividades que sean atractivas para el lector (Landeros, 2014). Existen distintas aplicaciones de acceso libre para la elaboración de un e-book, como: Canva, Flipsnak, entre otras. Dadas todas estas posibilidades, los eBooks pueden ser usadas como TAC, al elaborarlos se desarrolla la creatividad el pensamiento reflexivo y crítico.

En la actualización del programa de Biología IV de la Escuela Nacional Preparatoria (ENP) de la Universidad Nacional Autónoma de México (UNAM) se propone contribuir a la formación del pensamiento científico y de una cultura biológica en el alumno, a través de la investigación experimental y bibliográfica con el uso de las TIC y las TAC.

Este proyecto se realizó para cubrir los contenidos conceptuales: 1.4 Sustentabilidad y servicios ecosistémicos: de abastecimiento, de regulación, apoyo y culturales y el tema, y 1.6 Tipos de ecosistemas. Además, se abordaron los contenidos actitudinales: 1.17 Valoración del respeto y la responsabilidad hacia todos los seres vivos y el ambiente y 1.18 Reconocimiento de la importancia de la toma de decisiones ambientales a partir del análisis de conceptos básicos de ecología pertenecientes a la Unidad 1 titulada: "Los seres vivos y el cambio climático".

El objetivo perseguido fue que el alumno investigue, comprenda y reflexione sobre las características e importancia de los ecosistemas de México, a través de la elaboración de un e-Book de acceso libre como herramienta TIC y TAC.

\section{DESARROLLO}

\subsection{INVESTIGACIÓN BIBLIOGRÁFICA DE LOS ECOSISTEMAS DE MÉXICO}

Estas actividades fueron realizadas en el ciclo escolar 2018-2019. En la fase de inicio los profesores presentaron el título del tema y el objetivo del proyecto. Éste se trabajó en equipos colaborativos de 5 a 6 integrantes. El proyecto tuvo una duración de 2 sesiones presenciales de 50 minutos cada una y 5 sesiones extraclase. A cada equipo se le designó un ecosistema mexicano perteneciente al tipo terrestre o acuático. 
Con la finalidad de que los alumnos investiguen sobre las características de los ecosistemas mexicanos visitaron la sala de "Biodiversidad" del Museo de Historia Natural de la Ciudad de México, en él, obtuvieron información e imágenes de los diferentes ecosistemas del país.

Para complementar su investigación, los alumnos realizaron una búsqueda de información en fuentes especializadas en temas de ecosistemas y sus servicios como: Biodiversidad mexicana, tesiUNAM, CONABIO y medios impresos. También, buscaron recursos multimedia: imágenes, videos y audios relacionados al tema. Se les indicó que citaran las fuentes y los recursos utilizados.

Con la finalidad de fomentar el trabajo colaborativo entre los alumnos crearon un documento compartido con la aplicación de Google Docs. Éste permite la edición y comunicación a distancia, además es una herramienta de andamiaje entre el profesor y el alumno. Para eso deberán configurar los permisos de edición correspondientes. Esta actividad refuerza en los alumnos, la escritura, redacción y capacidad de síntesis de un tema. En la Figura 1 se muestran ejemplos de los documentos elaborados por los alumnos.

Figura 1. Ejemplo de documentos compartidos hechos con Google Doc y evidencia de comunicación por medio del chat de la misma aplicación.

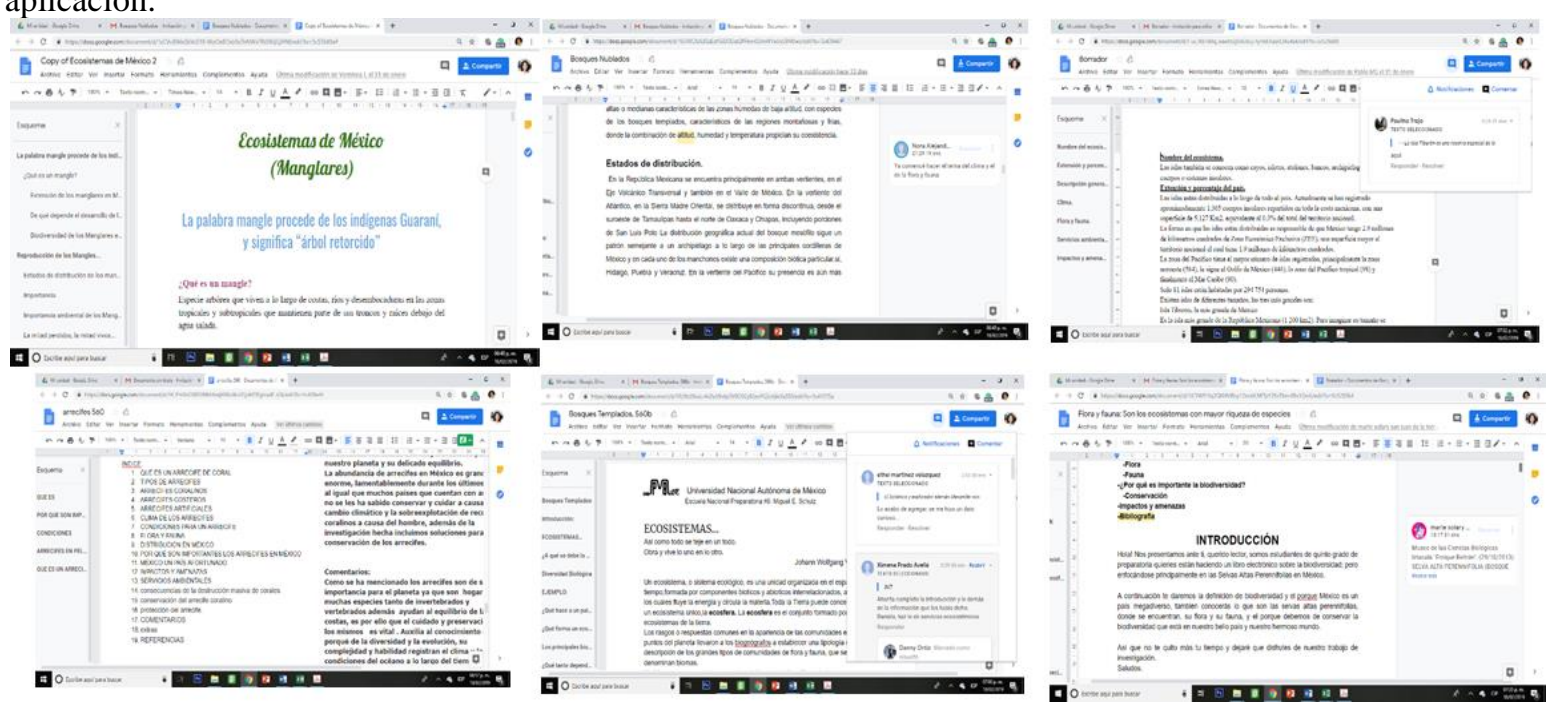

\section{ELABORACIÓN DEL EBOOK}

A partir de los documentos compartidos, los alumnos elaboraron un e-Book. La actividad se evaluó la edición, elección de los recursos multimedia, redacción y síntesis; mediante una rúbrica (Tabla 2). Además, se sugirió la aplicación de “Canva” para la elaboración del producto final, sin embargo, los alumnos también utilizaron otros programas como "Flipsnak".

A continuación, se muestran algunos productos elaborados por los alumnos (Figura 2, 3 y Tabla 1). Los e-Books contienen diferentes características: la extensión y porcentaje en que ocupa el ecosistema dentro del país, una descripción general, estados de distribución, clima, flora y fauna, servicios ambientales, y por último, impactos y amenazas de un ecosistema de México. Como parte del cuerpo del 
e-Book, los alumnos añadieron fotos de su visita al museo, así como información recabada del museo. Cabe resaltar que los alumnos protegieron su obra con una licencia internacional de "Creative Commons".

Figura 2. Ejemplos de e-Books elaborados por los alumnos. Cada equipo lo realizó de un tipo de ecosistema diferente.

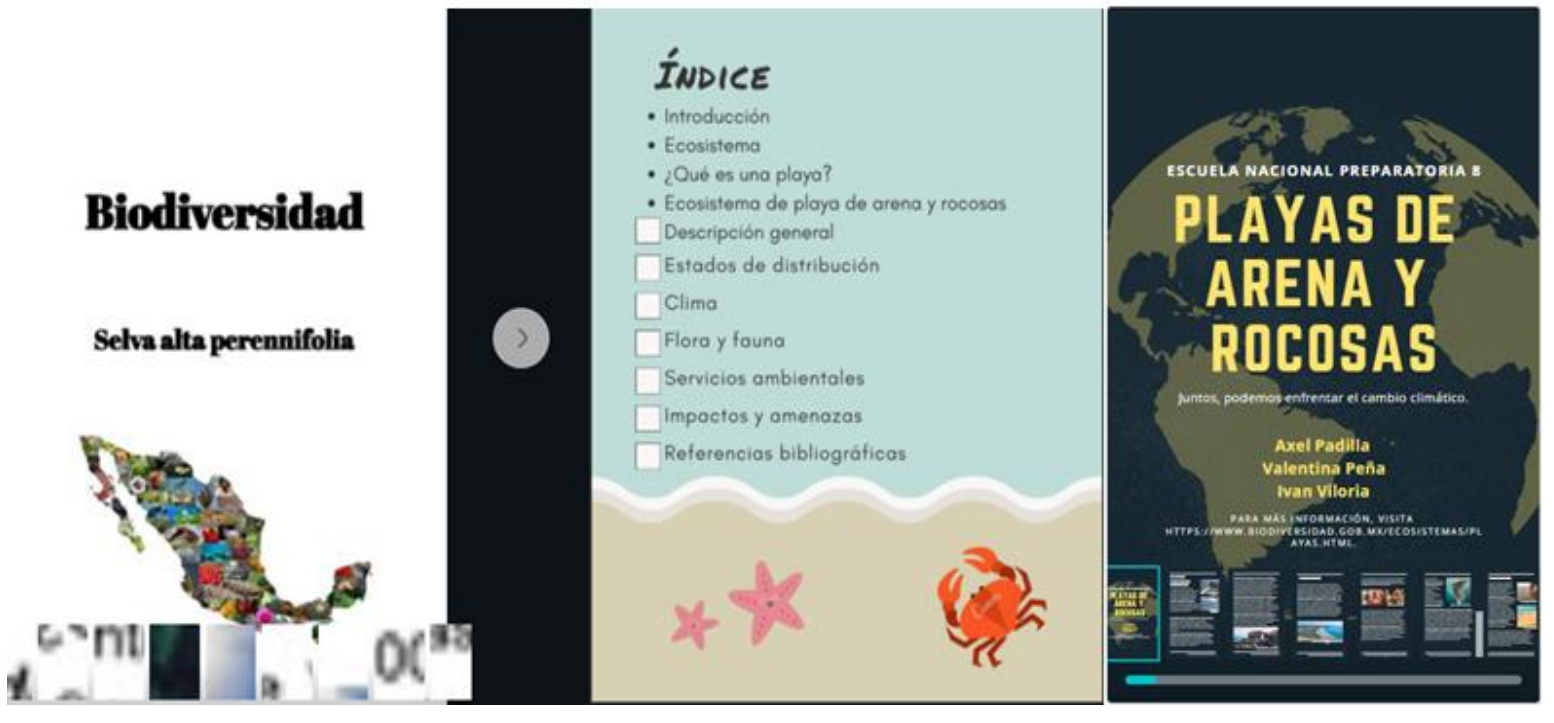

Figura 3. Ejemplo de e-Book con licencia Creative Commons.

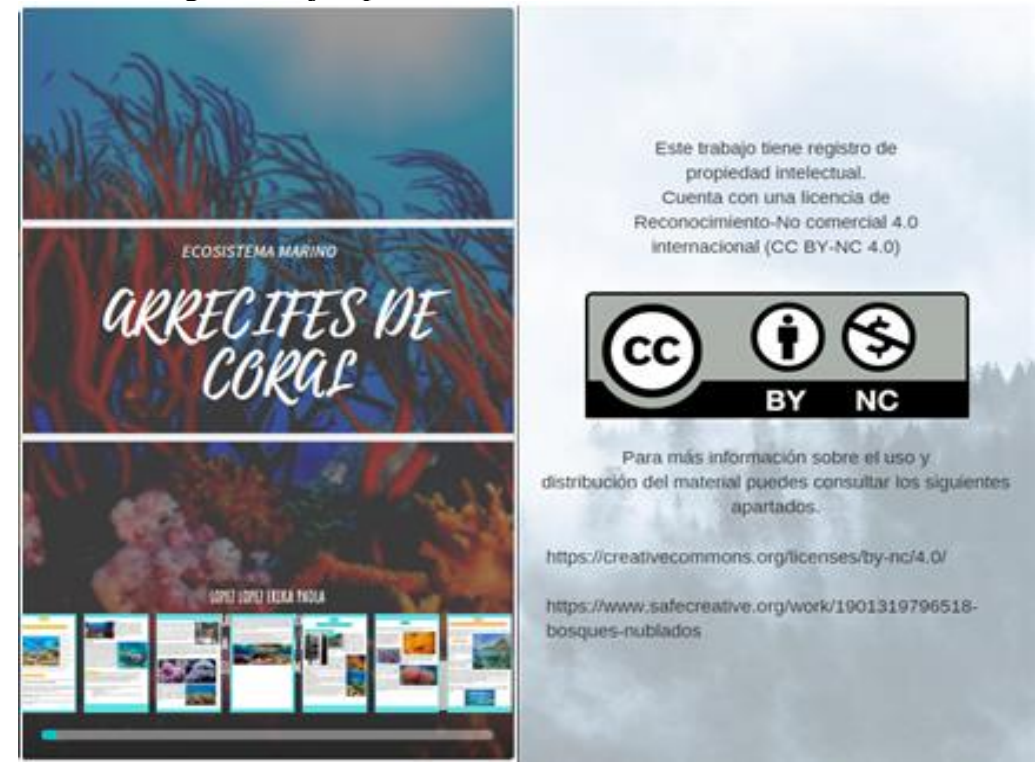

Tabla 1. Enlaces a algunos trabajos de alumnos

\begin{tabular}{|c|c|}
\hline Título del trabajo & Enlace \\
\hline $\begin{array}{l}\text { Arrecifes } \\
\text { comunidades } \\
\text { coralinas } \\
\end{array}$ & $\begin{array}{l}\text { https://www.flipsnack.com/thaniaprofile/arrecifes-y- } \\
\text { comunidades-coralinas.html }\end{array}$ \\
\hline $\begin{array}{ll}\text { Manglares } & \text { y } \\
\text { Humedales } & \end{array}$ & $\begin{array}{l}\text { https://www.canva.com/design/DADSAZdrZ2c/J5YWTpmjTfo } \\
\text { AH6doXpxJ-w/view }\end{array}$ \\
\hline
\end{tabular}




\begin{tabular}{|c|c|}
\hline Bosque mesófilo & $\begin{array}{l}\text { https://www.canva.com/design/DAEfKARBntI/GUfVtSFwBH_s } \\
\text { bp0piCfcxg/view?utm_content=DAEfKARBntI\&utm_campaign } \\
\text { =designshare\&utm_medium=link\&utm_source=publishsharelink }\end{array}$ \\
\hline Arrecifes de Coral & $\begin{array}{l}\text { https://www.canva.com/design/DADRu- } \\
\text { mXwI8/fW_zwbnC4kpzLwezkkHffA/view }\end{array}$ \\
\hline $\begin{array}{l}\text { Selva alta } \\
\text { perennifolia }\end{array}$ & $\begin{array}{l}\text { https://www.canva.com/design/DADSAo2j65M/WXR9cp6QiFpI } \\
\text { nyLqUw88pQ/edit\#7 }\end{array}$ \\
\hline $\begin{array}{l}\text { Playas de arena y } \\
\text { rocosas }\end{array}$ & $\begin{array}{l}\text { https://www.canva.com/design/DAEfKNESfCQ/zwWKaDkeBz3 } \\
\text { NyhGTBWLpVQ/view?utm_content=DAEfKNESfCQ\&utm_ca } \\
\text { mpaign=designshare\&utm_medium=link\&utm_source=publishs } \\
\text { harelink }\end{array}$ \\
\hline Pastizales & $\begin{array}{l}\text { https://www.canva.com/design/DAEfKPgx10c/0r5rGH- } \\
\text { komujYZM45jBymQ/view?utm_content=DAEfKPgxl0c\&utm_c } \\
\text { ampaign=designshare\&utm_medium=link\&utm_source=publish } \\
\text { sharelink }\end{array}$ \\
\hline
\end{tabular}

\section{PRESENTACIÓN DEL E-BOOK FRENTE A GRUPO Y CONCLUSIONES GENERALES.}

Los alumnos presentaron el producto final frente a sus compañeros en el salón de clases (Figura 4). Las presentaciones tuvieron una duración de 10 minutos más 5 minutos de preguntas. Durante la plenaria el profesor y alumnos discutieron sobre los bienes y servicios que aportan los diferentes ecosistemas, la importancia de preservar y de explotación sostenible. Además cada equipo proporcionó información sobre las medidas de cuidado especial para el ecosistema estudiado.

Figura 4. Presentación de los e-Books en plenaria.

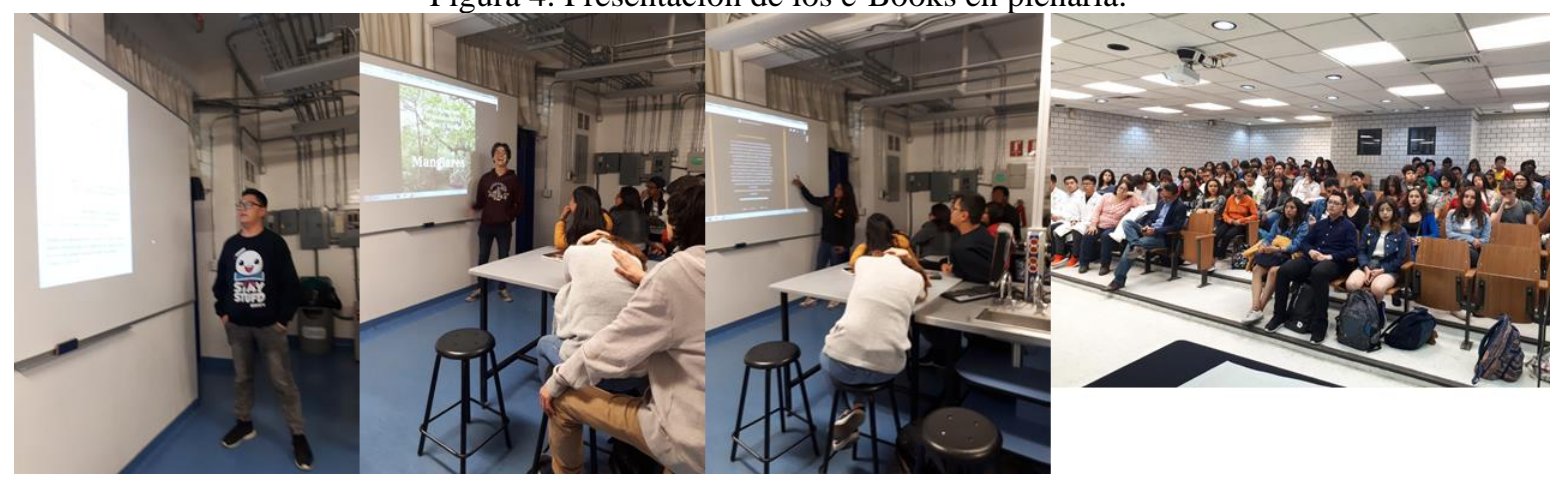

\section{CONCLUSIONES}

La presentación del producto final es resultado de la creatividad, análisis y síntesis para obtener un e-Book atractivo, fácil de leer y algunas veces con contenido multimedia. Para lo cual tuvieron que buscar la información, seleccionarla y tomar una decisión. Por ello, este tipo de aprendizaje basado en proyectos es uno de los más empleados en pedagogía ya que promueve el aprendizaje centrado en el trabajo del alumno. 
En este proyecto, el papel del profesor fue revisar que la información procedente de fuentes confiables y fuese la pertinente al tema y siguiera los lineamientos de la rúbrica. Por lo que, el alumno se involucra en la generación de todos los contenidos y de su difusión.

Este tipo de proyectos tiene la capacidad de integrar varios tipos de contenidos. En este caso fueron dos conceptuales: 1.4 Sustentabilidad y servicios ecosistémicos: de abastecimiento, de regulación, apoyo y culturales y el tema, y 1.6 Tipos de ecosistemas.

Se desarrollaron varios contenidos procedimentales, debido a que los alumnos emplearon y desarrollaron habilidades en el uso de TIC, mediante las herramientas de Google, para facilitar el aprendizaje colaborativo, las tareas en equipo y la comunicación durante su realización.

Se desarrollaron dos contenidos actitudinales ya que valoran la importancia de la conservación de los ecosistemas y proponen nuevas soluciones de sustentabilidad.

Finalmente, los e-Books son TAC que promueven la creatividad y capacidad de síntesis durante el diseño, escritura y edición del material. Por lo que pueden ser una valiosa herramienta tecnológica para cualquier docente que requiera de actividades integradoras cuyo protagonista sea el alumno. 


\section{REFERENCIAS BIBLIOGRÁFICAS.}

Biodiversidad mexicana. https://www.biodiversidad.gob.mx/Recuperado el 31 de marzo de 2019 CONABIO. https://www.gob.mx/conabio Consultado el 31 de May de 2019.

Destebasi, F. (2015). A Literature Review: The impacts of digital tools on the process of teaching and learning in middle school. Erzincan Üniversitesi Sosyal Bilimler Enstitüsü Dergisi (ERZSOSDER) ÖSII: $107-122$.

Diseña un libro digital profesional con Canva. https://www.canva.com/es_mx/crear/libros-digitales/. Recuperado el 28 de mayo de 2019.

Flipsnack. https://www.flipsnack.com/ consultado 31 May 2019

Google Docs. Español como utilizar Google documentos. https://www.youtube.com/watch?v=pUEwfZaumc8 Consultado el 31 de marzo de 2019

Landeros Alvarado, Paulina, 2014 Cómo se hace un eBook mitos y verdades sobre la formación tipográfica de los libros electrónicos / tesis que para obtener el título de Licenciado en Ciencias de la Comunicación (Periodismo). Universidad Nacional Autónoma de México. Facultad de Ciencias Políticas y Sociales.

Programa Biología IV ENP. http://dgenp.unam.mx/planesdeestudio/quinto-2017/1502_biologia_IV.pdf. Recuperado 28 de mayo de 2019.

Ortiz Marín P., Giménez Velázquez A. B., Rabal Alonso J. M. 2021. Percepción del profesorado acerca de la importancia del uso de las tic para favorecer la inclusión del alumnado. South Florida Journal of Development. Vol. 2 No. 2. DOI: https://doi.org/10.46932/sfjdv2n2-089

Santana Sardi G. A., Castro Coello R. L., Gutiérrez Santana J. A., Briones Palacios Y. M., Mawyin Cevallos F. A. 2021. Criterios sobre las tecnologías del aprendizaje y conocimiento (tac) en tiempo de pandemia covid-19. South Florida Journal of Development. Vol. 2 No. 2. DOI: https://doi.org/10.46932/sfjdv2n2-053

TesiUNAM. http://oreon.dgbiblio.unam.mx/F?RN=423429996. Consultado el 31 de marzo de 2019 
Tabla 2. Rúbrica de evaluación del e-Book.

\begin{tabular}{|c|c|c|c|c|}
\hline Valoración & 4 puntos & 2 punto & O puntos & Puntos \\
\hline $\begin{array}{l}\text { Profundización } \\
\text { del tema }\end{array}$ & $\begin{array}{l}\text { Descripción clara y } \\
\text { sustancial del tema y } \\
\text { buena cantidad de } \\
\text { detalles. }\end{array}$ & $\begin{array}{l}\text { Descripción ambigua } \\
\text { del tema, algunos } \\
\text { detalles que no clarifican } \\
\text { el tema. }\end{array}$ & \begin{tabular}{l}
\multicolumn{2}{l}{ Descripción } \\
incorrecta del tema, \\
sin detalles \\
significativos \\
escasos.
\end{tabular} & \\
\hline $\begin{array}{l}\text { Redacción de la } \\
\text { información }\end{array}$ & $\begin{array}{l}\text { Tema bien organizado } \\
\text { y claramente } \\
\text { presentado, así como } \\
\text { de fácil seguimiento. } \\
\text { Con muy buena } \\
\text { redacción }\end{array}$ & $\begin{array}{l}\text { Tema bien focalizado, } \\
\text { pero no suficientemente } \\
\text { organizado. En general } \\
\text { buena redacción, pero } \\
\text { con algunas } \\
\text { incoherencias. }\end{array}$ & 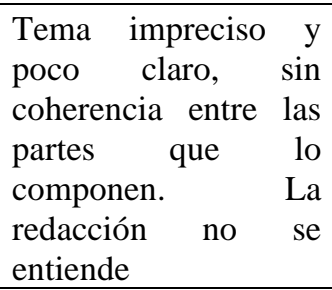 & \\
\hline Texto & $\begin{array}{l}\text { Claro y relevante al } \\
\text { tema }\end{array}$ & $\begin{array}{l}\text { Algunos errores en el } \\
\text { texto, la mayor parte del } \\
\text { material es relevante al } \\
\text { tema }\end{array}$ & $\begin{array}{lr}\text { Textos } & \text { poco } \\
\text { pensados, irrelevante } \\
\text { al tema }\end{array}$ & \\
\hline $\begin{array}{l}\text { Calidad } r \text { del } \\
\text { Diseño, Estética } \\
\text { del e-Book y uso } \\
\text { multimedia }\end{array}$ & $\begin{array}{l}\text { Buen diseño, uso de } \\
\text { formato de texto y } \\
\text { agradable a la lectura. } \\
\text { Uso excelente de } \\
\text { medios variados. } \\
\text { Demuestra } \\
\text { creatividad }\end{array}$ & $\begin{array}{l}\text { Regular diseño, poco } \\
\text { formato de texto. } \\
\text { Incluye algunos medios, } \\
\text { utiliza al menos un } \\
\text { medio, muestra cierta } \\
\text { creatividad. }\end{array}$ & $\begin{array}{l}\text { Diseño muy pobre, sin } \\
\text { formato de texto. } \\
\text { Pobre en el uso de } \\
\text { medios, poco o nada } \\
\text { creativo }\end{array}$ & \\
\hline $\begin{array}{l}\text { Presentación oral } \\
\text { del eBook }\end{array}$ & $\begin{array}{l}\text { Bien preparada buen } \\
\text { conocimiento del } \\
\text { tema contenido en el } \\
\text { eBook, capaz de } \\
\text { explicarlo y de } \\
\text { responder preguntas. }\end{array}$ & \begin{tabular}{lr}
\multicolumn{2}{l}{ Ligeramente preparada } \\
algunos conocimientos \\
del tema contenido en el \\
eBook, \\
responder \\
preguntas.
\end{tabular} & $\begin{array}{l}\text { No se ha preparado no } \\
\text { se comprende el tema } \\
\text { contenido en el } \\
\text { eBook, no pueden } \\
\text { responder preguntas. } \\
\text { Mera lectura de textos }\end{array}$ & \\
\hline $\begin{array}{l}\text { Créditos } \\
\text { Bibliografía }\end{array}$ & $\begin{array}{l}\text { Se atribuye la autoría } \\
\text { a todos los recursos } \\
\text { multimedia y se } \\
\text { incluye bibliografía } \\
\text { confiable. }\end{array}$ & $\begin{array}{l}\text { Se atribuye la autoría a } \\
\text { la mayoría de los } \\
\text { recursos multimedia y se } \\
\text { incluye bibliografía } \\
\text { poco confiable. }\end{array}$ & $\begin{array}{l}\text { No se reconoce la } \\
\text { autoría de la mayoría } \\
\text { de los recursos y no } \\
\text { incluye bibliografía } \\
\text { confiable }\end{array}$ & \\
\hline \multicolumn{4}{|c|}{ TOTAL } & \\
\hline
\end{tabular}

